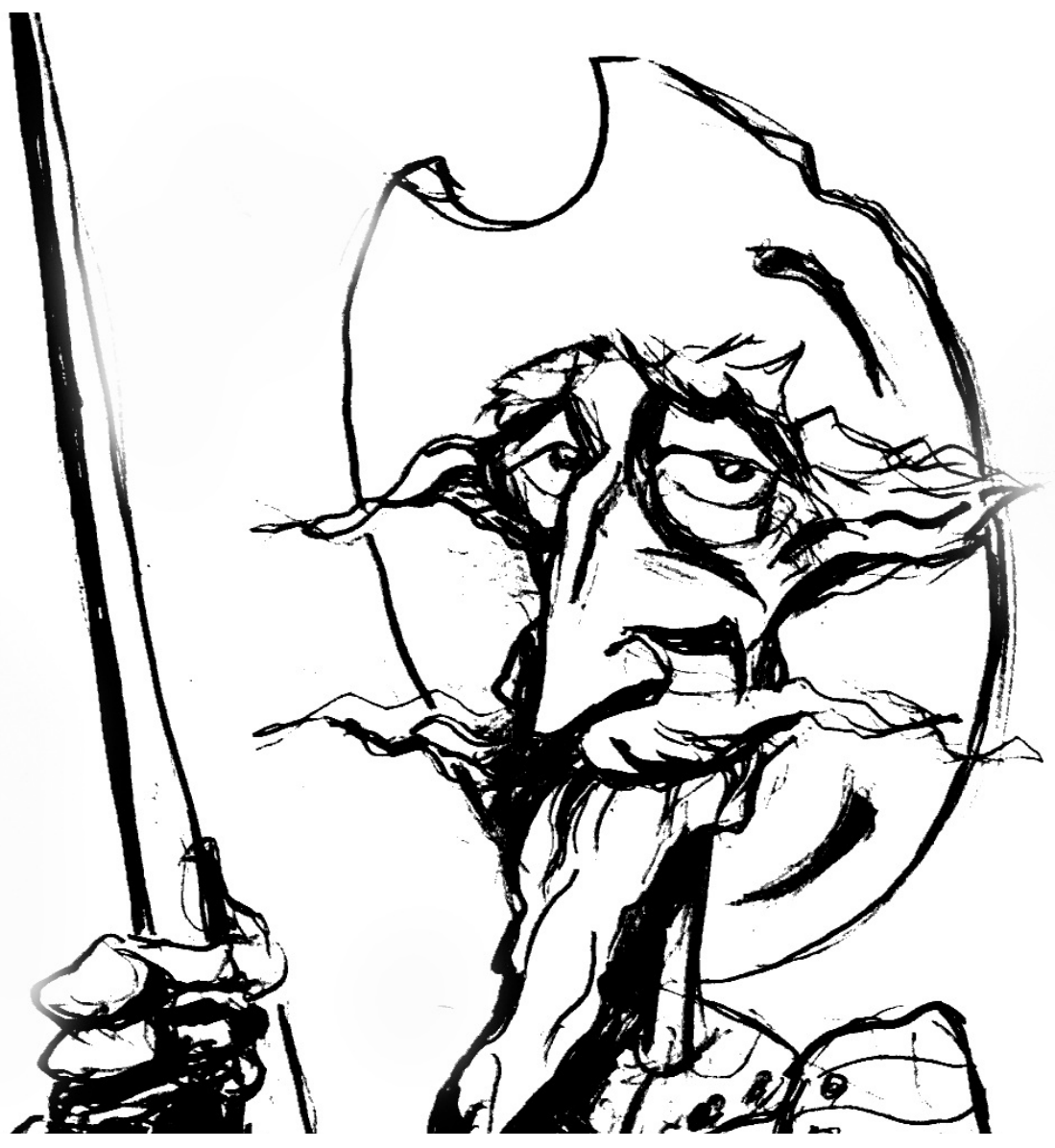

La renovación del peronismo en Neuquén. Tensiones, conflictos y ruptura: la JDP, 1983-1989

[Orietta Favaro] 



\title{
La renovación del peronismo en Neuquén. Tensiones, conflictos y ruptura: la JDP, 1983-1989
}

\section{The Renewal of Peronism in Neuquen. Tensions, Conflicts and Rupture: the JDP, 1983-1989}

\author{
ORIETTA FAVARO
}

\section{Resumen}

El objetivo del artículo es analizar la corriente interna de renovación peronista dentro del PJ en Neuquén durante la transición democrática, que provocó tensiones, conflictos y la ruptura en el entramado, con la conformación de un partido que intentó presentarse -sin éxito- como otro peronismo provincial: Justicia, Democracia y Participación (JDP,1986). La propuesta se enmarca en el contexto nacional-regional tanto político como sindical hacia los años ochenta y en el sistema político local en el que predominaba el MPN, un partido que nació como neoperonista (1963), le disputó -con éxito- al Frejuli la representación del peronismo (1973) y se convirtió en entramado provincial en los ochenta. El trabajo se realiza a partir del cruce entre la historiografía nacional-local, el diario de mayor tirada regional, revistas locales y algunos testimonios de la época.

Palabras clave

Tensiones; conflictos; rupturas; peronismo; Neuquén

\begin{abstract}
The aim of this article is to analyze the internal current of Peronist renewal within the PJ in Neuquén during the democratic transition, which caused tensions, conflicts and the break of the network, with the formation of a party that tried to present itself unsuccessfully- as another provincial Peronism: Justice, Democracy and Participation (JDP, 1986). The proposal is framed in the national-regional context, both political and trade union towards the eighties and in the local political system dominated by the MPN, a party that was born as a neo-Peronist (1963), successfully disputed the representation of Peronism with Frejuli (1973) and became a provincial framework in the eighties. The work is based on the cross between national and local historiography, the newspaper with the largest regional circulation, local magazines and some testimonies of the time.
\end{abstract}

Keywords

Tensions; conflicts; ruptures; peronism; Neuquén

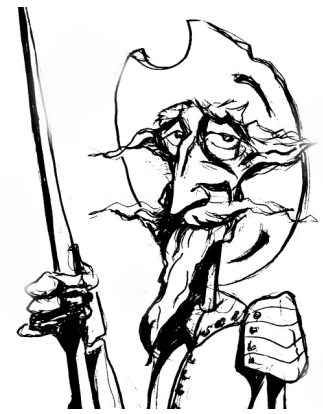

Recibido con pedido de publicación el 19 de diciembre de 2019

Aceptado para su publicación el 20 de febrero de 2020

Versión definitiva recibida el 5 de abril de 2020

Orietta Favaro, Universidad Nacional del Comahue, Neuquén, Argentina; e-mail: oriettafavaro@speedy.com.ar

* Agradezco los comentarios y sugerencias de los evaluadores anónimos de Revista Prohistoria

Esta obra se publica bajo licencia Creative Commons. Atribución-NoComercial-CompartirIgual $(\mathrm{cc})$ EY-NC-sA $\underline{4.0 \text { Internacional }}$

Favaro, Orietta "La renovación del peronismo en Neuquén. Tensiones, conflictos y ruptura: la JDP, 1983-1989", Prohistoria, Año XXIII, núm. 33, jun. 2020, pp. 177-201. 


\section{El problema}

El Peronismo en Argentina es objeto permanente de estudio y la historiografía explica su desarrollo y actores a partir de acontecimientos en general ocurridos en Buenos Aires, aunque le otorga a estos una dimensión nacional. Ello se dio en especial para la explicación del primer peronismo (1946-1955), ya que en el caso del segundo, 1973-1976, la complejidad del escenario central dio lugar a una más amplia investigación que incluyó la complejidad de la situación política en algunas provincias (Servetto, 2010).

En los años ochenta, tomando como punto de partida el primer gobierno democrático (1983) luego de dictadura militar (1976-1983), la literatura no solo es abundante, sino que recorre un sinfín de temas en la mayoría de las provincias argentinas, tanto en libros como en revistas nacionales y extranjeras. En ellos, se exponen resultados de investigaciones, algunas cercanas a los temas tratados y otros más alejados vinculados a la situación socio-política en las primeras décadas de democracia. Un punto nodal de los estudios es la transición democrática en Argentina, el triunfo del Radicalismo (UCR) y la derrota del Justicialismo (PJ) y se trata -entre otros- no solo propuestas y resultados del primer gobierno democrático sino el impacto de la derrota en el PJ.

En la última década, una serie de producciones, muestran nuevamente a la historiografía interesada en investigaciones sobre renovación del Peronismo entre 1983 y 1989. Varios trabajos se realizaron sobre el tema, entre los más recientes,importa destacar el aporte de artículos (Basso, 2011; Garategaray, 2010, 2013; Ferrari, 2017) y de compilaciones (Ferrari y Mellado, 2016). Esta última obra, además de explicar la situación en ocho provincias y en la ciudad de Buenos Aires, concluye con un ejercicio de síntesis, en el que se compara actores, estrategias y disputas, agrupando distritos en los que surgen circunstancias que permiten observar coincidencias o diferencias (Brachetta, 2016). De este modo, se entiende con mayor precisión,entre otras cuestiones, el grado de fragmentación del PJ, la fuerza de la ortodoxia peronista, el rol de los gremios o sindicatos (que no fue el mismo en provincias con mayor industrialización que en las periféricas), la lucha del sector renovador por imponerse, el direccionamiento del proceso general según los sucesos en la provincia bonaerense y de la capital; todo ello muestra el grado de complejidad del Peronismo de la década del ochenta.

Durante mucho tiempo estuvo ausente de la bibliografía nacional, explicaciones sobre el Peronismo en provincias periféricas, en particular las que fueron Territorios Nacionales entre 1884 y 1955 -constituían el 43 \% del espacio nacional- y en las que el PJ tuvo un rol significativo al definir el otorgamiento de la ciudadanía política al convertirlas en nuevas provincias argentinas. Con la edición de una serie de libros hace dos décadas (Macor y Tcach, 2003; Rafart y 
Mases, 2003) y varios artículos (Favaro y Arias Bucciarelli, 1999), se cubrió, en parte, ese vacío historiográfico y se observó sobre la necesidad de evitar generalizaciones que siempre parecían tener como escenario la capital del país y/o sus provincias más próximas. En primer lugar, porque los estudios dieron muestras de la diferencias entre los actores y las prácticas políticas, así como la importancia en los estudios, de determinados documentos y repositorios, entre otros, la prensa local, los libros copiadores de los gobernadores territoriales, los informes del Ministerio del Interior del cual dependían,los testimonios orales y los archivos judiciales. Así se inició en la historia del Peronismo en el país,un avance en las reconstrucciones históricas -por historiadores y cientistas sociopolíticos- que permitieron enriquecer una multiplicidad de problemas.

Sin embargo, continúa la carencia de artículos, capítulos de libros o libros, que tratara la vida de los partidos políticos del norte de la Patagonia, en particular de Neuquén y Río Negro, a excepción del caso del Movimiento Popular Neuquino (MPN), una de las siete provincias en las que no hubo alternancia en el ejecutivo local desde 1963 a la actualidad. Este tema, ampliamente estudiado, permitió concretar explicaciones sobre su origen, derrotero y fuerza territorial (Favaro, 2017a). Sobre el resto de los partidos, Peronismo, Radicalismo y otras experiencias provinciales, los análisis se focalizan en la dimensión electoral, la política de coaliciones, el accionar del partido dominante y sus dirigentes, desde el regreso a la democracia hasta avanzado el siglo XX (Camino Vela y Rafart, 2012). Resulta notable la escasa referencia al Peronismo en la transición democrática y sus intentos de renovación en Neuquén entre 1983 y 1989 (Camino Vela y Rafart, 2014; Favaro y Iuorno, 2013; Iuorno, 2016, Iuorno et al, 2017; Arias Bucciarelli, 2011; Rafart, 2016, 2018).

En este orden, el objetivo del artículo es analizar la corriente interna de renovación peronista dentro del PJ en Neuquén durante la transición democrática, que provocó tensiones, confictos y la ruptura en el entramado, con la conformación de un partido que intentó presentarse como otro peronismo provincial: Justicia, Democracia y Participación (JDP,1986). La propuesta se enmarca en el contexto nacional-regional tanto político como sindical hacia los años ochenta y en el sistema político local en el que predominaba el MPN, un partido que nació como neoperonista (1963), le disputó -con éxito- al Frejuli la representación del peronismo (1973) y se convirtió en entramado provincial en los ochenta.

La propuesta intenta mostrar la complejidad de la sociedad neuquina para aceptar la emergencia de otro peronismo al ya consolidado,el MPN, que si bien no levantó las consignas justicialistas en 1983, tampoco parecía vaciar al entramado de esos contenidos. 
El trabajo se realiza a partir del cruce entre la historiografía nacionallocal, la información que surge del diario de mayor tirada regional, revistas locales y los testimonios de algunos actores de la época. Esta metodología se vincula a la inexistencia de repositorios y archivos con material documentaltestimonial del partido seleccionado para el estudio,de modo que analizar el tema implica acudir a fuentes alternativas y triangular información para explicar el problema.

\section{El escenario politico-sindical de Argentina}

El período seleccionado para el presente estudio corresponde a la denominada transición democrática, acto único de un proceso, extendido en el tiempo, cuya fase inicial fue el comienzo de la descomposición del régimen militar y la segunda, la instalación de un gobierno democrático; democracia que no se consolidó hasta tanto atravesó un tercer momento que -en medio de tensiones y conflictos- quedó asegurada. La historiografía si bien difiere sobre el inicio del proceso (1980/81), coincide en que es anterior al desenlace de la aventura de Malvinas (1982), ya que los militares del "Proceso de Reorganización Nacional" (PRN), mantuvieron contactos políticos antes y durante el conflicto. La dictadura no impidió que tanto el Peronismo como el Radicalismo y otros partidos, en diferentes espacios, mantuvieran reuniones, deliberaciones y presentaciones públicas y/ o privadas; así se conformó la Multipartidaria (1981), con la cual resurgía la política desde la ilegalidad. La derrota en la guerra, brutalmente cayó sobre todos, no solo en los que adhirieron y el régimen inició su total descomposición. Las FF.AA tuvieron que transferir el gobierno en las condiciones que menos deseaban. Los partidos políticos lanzados a la disputa electoral tomaron distancia del gobierno como el Radicalismo con Raúl Alfonsín planteando -entre otras cuestiones- denuncias por la violación a los derechos humanos. El 30 de octubre triunfó quebrando un ciclo de la historia argentina dominado por el Peronismo, interpelando la sociedad desde otro lugar y con ordenadores de mediatización de la política. El PJ se impuso en doce provincias y la UCR en ocho. Solo en tres triunfaron partidos locales, entre ellas, Neuquén.

El Radicalismo con Alfonsín y los dirigentes del partido hicieron una interesante lectura de la composición social del momento, ya que el nuevo contexto permitía romper con el pasado y crear nuevos grupos de votantes. Había que reconocer e incorporar a la clase obrera, apelar a la democracia como forma legítima de resolución de problemas y conflictos, acompañada de la defensa de los derechos humanos, cuestionando el poder de las corporaciones: sindicatos, Fuerzas Armadas e Iglesia. Se incorporó el concepto de la "gente" como contraposición al pueblo, pero además se tuvo en cuenta los casi cinco millones de votantes nuevos,surgió el independiente (que no tenía identidades fijas) y los nuevos ciudadanos (Vommaro, 2006). El partido era el sujeto político 
que Alfonsín -durante años- pretendía construir con el objetivo de sacarlo de su rol secundario en la escena política: había que disputar gobierno y poder (Delgado, 2003).

El PJ parecía quedar recluido en los viejos votantes y en la clase obrera aunque aún valía el peso de la tradición en el nuevo ciclo político- pero debía reconocer el cambio de época y sus resignificaciones, porque se visualizaba que el Radicalismo comenzaba “...a transitar un camino que lo convertía en alternativa políticamente válida primero frente al peronismo 'anacrónico' asociado a valores poco democráticos y por ello cercano a viejas modalidades del ejercicio político y al propio radicalismo después" (Garategaray, 2013).

Recordemos que luego de la dictadura, el PJ emergió como un partido de base sindical, en el que los sindicatos -la principal fuerza organizativa y de expresión del peronismo durante esos años- controlaban la selección de candidatos, ya que por su posición ventajosa al vacío de la conducción después de 1974 y la corporativización con la caída de López Rega (1975) se robusteció la hegemonía sindical. Si bien en la dictadura, la política estaba prohibida, los sindicatos "financiaban" lo que se podía hacer. El dominio nacional de estas asociaciones fue muy importante, no solo en las principales provincias de litoral y pampa húmeda, sino en el resto del país, de modo que Lorenzo Miguel (UOM) y Diego Ibáñez (SUPE) estaban a la cabeza de toda gestión para la política y lo político (Levitsky, 2003). Simultáneamente es necesario destacar el desafío al propio peronismo en su rama sindical y/o política por el desenvolvimiento de la desindustrialización selectiva (Castellani, 2004) y consiguiente declive de la clase obrera durante la dictadura, que combinó la represión-desaparición con la reestructuración económica. Se diezmó a los trabajadores industriales en varios sectores y quebraron empresas con el auge de los grupos comerciales, financieros y de servicios; es decir, se produjo enormes transformaciones en los sectores populares urbanos, con una clase industrial más reducida y sectores populares urbanos más heterogéneos y fragmentados. Estos cambios, modificaron también las tradicionales coaliciones básicas del PJ, ya que la cantidad de afiliados se redujo y se puso en cuestión al sindicalismo industrial como vínculo del peronismo con la clase obrera urbana (Levitsky, 2003).

Después de la derrota de 1983 se originaron turbulencias en el Peronismo, se lo identificaba con la vieja guardia política y sindical: las 62 Organizaciones, Lorenzo Miguel y Herminio Iglesias. Varios dirigentes, entre ellos, Cafiero, De la Sota, Grosso, Unamuno, plantearon cambiar la imagen, liberar al peronismo de su estilo autoritario, empezar a habitar la democracia y el pluralismo. Los dirigentes planteaban necesario hacer una renovación, con una revolución en paz, aceptando el disenso y conviviendo políticamente. De todos modos, salieron a la luz los varios peronismos que discutían la conducción, el liderazgo y la institucionalización del justicialismo; es decir, cómo reemplazar 
a Perón que unificaba a sectores impensados garantizando las partes. Varios dirigentes veían a esta tarea como una labor altamente difícil pero igual la emprendieron. La empresa debía no solo reivindicar a Perón y la doctrina, sino revalorizar la democracia internalizando sus valores, alejarse del autoritarismo y de las contradicciones irresoluble que se diluían con el líder.

Se pusieron en marcha los congresos partidarios del Peronismo, se observó un clima rupturista y se publicó "Por qué nos vamos" (Revista Unidos,1985) en el que se acusó al partido de no adecuarse al nuevo clima de ideas. Quedaron dos grupos muy heterogéneos: el ortodoxo y el renovador que sin discutir qué entendían por cada concepto-, llevó a este último renunciar a la afiliación al PJ pero no a la identidad peronista. La renovación peronista se formalizó el 21 de diciembre de 1985 a nivel nacional -entre otros- con Cafiero, Grosso, Menen, Manzano, Bordón, de la Sota y Massei.

Las grietas se profundizaron dentro de la renovación del PJ a partir del Acto en la Plaza Once (23/05/86), cuando quedó claro que Menem pretendía ser el candidato a presidente en 1989. Luego del congreso partidario en Tucumán, Menem comenzó a armar listas para competir en las internas provinciales, con su línea (Federalismo y Liberación-Línea Nacional Rojo Punzó), nucleando o cooptando discidentes en cada distrito, frente a Cafiero que convocaba mayoritariamente a jóvenes, con discursos progresistas, pretendiendo re fundar al PJ (Basso, 2011: 819-821). Como se sabe, en la interna del Justicialismo en julio de 1988, triunfó la fórmula Menem-Duhalde.

El proceso nacional hasta aquí descripto tuvo matices en cada distrito o provincia y la institucionalidad operó con eficacia, estimulando en todas el re cambio de dirigentes y de prácticas. Con cierta lentitud o con urgencia, según las dificultades halladas, en la medida que el peronismo renovador avanzaba, se aceleraban las tensiones y disputas en cada espacio subnacional, se producían fracturas -en muchas oportunidades sin el debate suficientesubordinando las cuestiones no resueltas por la urgencia electoral.

\section{El Neuquén pos dictadura. Escenario social-sindical y político}

Durante la dictadura, al privatizarse la escena pública, desaparecieron las maneras convencionales de hacer política, pero se crearon nuevas, lugares velados y vedados en los que nuevos y viejos actores continuaron accionando. No desapareció la política, sino que se transformó su práctica. Por una parte, en los años 1980 tuvo un rol importante la diócesis neuquina de la Iglesia Católica ya que se convirtió en una institución de la que emergieron nuevos actores -las organizaciones defensoras de Derechos Humanos (DD.HH)-, favoreciendo su acción política (Azconegui, 2019). La Iglesia neuquina actuó a través de diferentes mecanismos, entre otros, la Revista Comunidad (RC) y la Pastoral 
Social (PS), ${ }^{1}$ también accionó como "paraguas" de protección a los que exiliados de países y provincias argentinas que se radicaban en Neuquén. Fue un territorio de encuentro, donde convergieron quienes luchaban y/o eran críticos a la dictadura; en el que participaron varios de los dirigentes de la política neuquina, en el marco de las ideas fundamentales del entonces Obispo Francisco De Nevares. ${ }^{2}$ La Iglesia tuvo participación en el rearmado de gremios como ATEN (Asociación de Trabajadores de la Educación de Neuquén), momento en que se comenzaba a re-organizar sindicatos intentando superar la débil CGT local, alejándose del partido hegemónico neuquino. ${ }^{3}$

Por otra parte, si bien el régimen autoritario condenó a la sociedad a un obligado invierno político, no impidió que algunos dirigentes neuquinos, en un grupo denominado Convergencia (1981), se reunieran, ${ }^{4}$ debatieran y generaran acciones. Eran 26 personas que se autoconvocaron, entre dirigentes políticos y sindicales, además de directivos de ACIPAN y de colegios de profesionales, aunados por la necesidad de revitalizar la política y con la consigna de repudio a la violación de los Derechos Humanos. En su primer comunicado, plantearon que "eran un grupo orgánico de expresión de la vocación de protagonismo de sus hombres y pretendía ser de referencia para una actividad generalizada de la civilidad provincial orientada hacia el rescate del estado de derecho y la vigencia de un auténtico proyecto nacional", proponiendo una toma de conciencia frente al pasado, al presente y al futuro. ${ }^{5}$

Si bien en los años setenta se intentó -sin éxito- organizar una CGT peronista en la provincia; carente de autonomía y de representatividad no logró consolidarse; antes bien, se reorientó hacia el MPN, partido que triunfó en las elecciones de 1973. La estructura sindical de este estado era débil, consecuencia del escaso desarrollo industrial -excepto en el petróleo y la construcción- y por los efectos de la dictadura. Hacia la década de 1980, también predominaban las 62 Organizaciones y los principales sindicatos eran delegaciones formales de las corporaciones más significativas; entre los más importantes cabe destacar el SUPE, la UOCRA, los trabajadores de la fruta en el Alto Valle y los de la administración pública (Rafart, 2016: 146). Por un lado, los petroleros respondían a Diego Ibáñez (SUPE) -también disputaban el control del sindicato

\footnotetext{
${ }^{1}$ La PS surgió en 1982. La asesora legal del Equipo Pastoral Neuquino, fue Raquel Fabani, una abogada que luego formó parte de la renovación peronista.

2 "Comisión Promotora", Revista Comunidad, 31/08/1981, “Los partidos políticos", Revista Comunidad, 08/12/1984. La RC se comenzó a editar en abril de 1981 y fue dirigida por un sacerdote del Servicio para la Comunicación y Capacitación de la Diósesis de Neuquén: SERPAC.

3 "Una corriente que quiere avanzar", Revista Calf, 04/02/1987.

${ }^{4}$ Las reuniones se hacían en la empresa ROR (Ramín, Osés y Ruiz: socios fundadores), que desde 1963 se dedicaba a la importación y distribución de artículos de bazar y juguetería en el Alto Valle de Río Negro y Neuquén.

5 “Convergencia”, Revista Calf, 08/09/1981.
} 
sectores no peronistas- pero se distinguía entre sus dirigentes a Ernesto Ramírez y Luis Novoa. ${ }^{6}$ Por otro, las huelgas en El Chocón, ${ }^{7}$ habían marcado una tradición combativa en los obreros de la construcción, que les permitió organizarse desde las bases eligiendo sus delegados y enfrentando, contrariamente a los petroleros, a los burócratas sindicales de la UOCRA. A pesar que se intentaba renovar la dirigencia de los gremios existentes y crear nuevos -comenzaba tibiamente a vislumbrarse la presencia a nivel nacional de la CGT Brasil con Saúl Ubaldini- el sindicalismo ortodoxo de la UOM y las 62 Organizaciones con Lorenzo Miguel, predominaron en la escena sindical regional de Argentina. Además el espacio sindical neuquino detentaba más contendientes y estaba en disputa, ya que no solo se encontraban los tradicionales dirigentes y militantes radicales, peronistas, demócratas cristianos o sectores de izquierda, sino que la contienda también la libraban los emepenistas. Tengamos en cuenta que este partido-estado (Favaro, 2017a: 115142) extendió sus dominancia a todos los rubros y sectores políticos-sociales para conservar y ampliar su gobierno y poder en la provincia.

En el espacio partidario, los principales entramados en Neuquén eran el MPN, el PJ y la UCR. Por el modelo constitucional, Neuquén tiene Cámara de Diputados -en los años de referencia solo con representación de mayoría y minoría- y el MPN venía triunfando en la provincia desde $1963,{ }^{8}$ año que por primera vez se presentó a elecciones durante la proscripción del peronismo. Cuando esta finalizó en 1973, triunfó sobre el Frente Justicialista de Liberación (FreJuLi). El Justicialismo había triunfado en todo el país, menos en Neuquén, por lo cual, el aparato electoral del nuevo gobierno nacional, acompañado por el sindicalismo peronista, se concentró en la provincia;pero en el ballotage, el MPN obtuvo el $60 \%$ de los votos. El MPN era el principal contrincante del FreJuLi, en parte, por las acciones del gobierno nacional y la falta de acuerdo en una fórmula y reparto de cargos en conjunto, que llevó a la derrota justicialista y al reconocimiento por parte de sus propios militantes, que Sapag había interpretado al peronismo en la provincia. Aunque el MPN no nació para desafiar el programa justicialista en 1973, se negaba a ser identificado con el Frente por sus desacuerdos con los mecanismos político-sindicales que utilizaba el partido a nivel central y la falta de definiciones acerca del federalismo. De un

\footnotetext{
${ }^{6}$ Novoa, obrero de YPF, fue secretario general del SUPE entre 1966-68 y 1973-75. Renunció a YPF, pero siguió ligado a la empresa como transportista de combustible, en "Nuestros candidatos son pueblo", Boletín del Partido Justicialista, núm.1, octubre 1983.

${ }^{7}$ Fueron dos huelgas entre diciembre de 1969 y marzo de 1970, en la construcción de la represa hidroeléctrica sobre el río Limay, por varias razones: salarios, seguridad, políticas, entre la empresa Impregilo Sollazo y el gremio UOCRA. En la solución intervino el Obispo De Nevares.

8 El MPN fue creado por dirigentes y funcionarios peronistas en 1961 con el compromiso de volver al tronco partidario cuando finalizara la proscripción del partido. Representaba a la mayoría de los peronistas neuquinos, excepto un pequeño grupo de Neuquén capital, con el que estuvieron permanentemente enfrentados.
} 
partido neoperonista (1961) pasó a ser el verdadero peronismo neuquino (1973), con todo el recelo y la desconfianza del gobierno nacional (Favaro, 2017b). De este modo, en 1973 ingresó el FreJuLi en la Cámara de Diputados; al poco tiempo mostraba divisiones internas en función del complejo escenario nacional de los años setenta. Comenzaba a observarse la heterogeneidad de la coalición electoral en Neuquén, en la que se destacaba como asesor del FreJuli, el abogado Oscar Massei.

Desde los inicios de 1980 el PJ de Neuquén, registraba actividad política en el marco de la cautela por la aún vigencia del régimen militar. Varios dirigentes, desde fines de 1981, intentaban reordenar el partido, entre ellos, Amalia Alonso, Jorge Diorio y Oscar Massei ${ }^{9}$ designados interventores por Deolindo Bittel a través del delegado de entonces, Carlos Vilches, que luego fue desplazado por Alberto Nievas. Este había arribado con las instrucciones del sector -sindical y político dominante en el nivel central- desalojando al triunvirato neuquino, en el marco del envío de representantes a las provincias con el propósito de observar las situaciones partidarias. La nueva realidad evidenciaba la complejidad del entramado político (PJ) y obligaba a algunos dirigentes, a re plantearse -aún sin vistas claras a la apertura democrática- el funcionamiento de la fuerza. Producida la convocatoria a elecciones, en junio de 1983, la interna justicialista en Neuquén, presentaba como candidatos a Alberto Nievas (interventor del partido) y a Oscar Massei, para la presidencia del partido; Angel Romero ${ }^{10}$ y Massei, como candidatos a gobernador.

Durante la campaña, Massei no solo cuestionaba la ortodoxia política y sindical, sino también al MPN porque lo consideraba representante de "un pequeño proyecto agotado carente de ideología, un inmenso vacío que se respaldaba en un disfrazado concepto de federalismo..." y al rol que debía

\footnotetext{
${ }^{9}$ Massei, profesional originario de Córdoba, se instaló en Neuquén en 1971 en un estudio de abogados. Sus principales actividades se vincularon al asesoramiento de la UOCRA -después de la gran huelga de El Chocón- atendiendo los problemas legales de las zonas aledañas (Cerros Colorados-Cutral Co-Zapala) y participando activamente en el peronismo neuquino. A fines de1973, instaló su sede laboral en el nuevo edificio de la central obrera, situación que mantuvo hasta 1979 en que la intervención al sindicato y la diferencias políticas con la misma, lo obligaron a retirarse del lugar. Cuando sobrevino la dictadura se destacó en su actividad profesional, en un contexto de represión y asumió la defensa legal de detenidos y desaparecidos. Por un lado, por la relación con Chávez (exiliada) y Arias, González y Buamscha (detenidos), por haber sido asesor del bloque del FreJuli entre 1973-76; por otro, había sido designado representante legal, entre otros, de docentes de la Universidad Nacional del Comahue (UNCo), como Marta De Cea y Pérez Lindo. Realizó una serie de juicios de amparo por las cesantías decididas por el Rector Remus Tetus, quien arribó a Neuquén en 1975 (T.O, O.M, 19/05/2018). Tetus había sido rector de la UNSur y formaba parte de la denominada "Misión Ivanissevich", cuyo objetivo era depurar ideológicamente las casas de estudios; tuvo a su servicio a sujetos como Raúl Guglielmietti, luego personal de Inteligencia del Ejército, que comandaría gran parte de los secuestros ocurridos durante la dictadura en el valle.

${ }^{10}$ Romero había sido el candidato a gobernador en Neuquén por el FreJuLi en 1973.
} 
tener el Estado, "el que se debe convertirse en una herramienta al servicio de la comunidad, dinamizando y dignificando al servidor público". ${ }^{11}$ Objetaba a los votantes del MPN porque "mientras la militancia justicialista sufría persecuciones por parte de la dictadura, otros con servilismo, estaban al lado del proceso"refiriéndose a los jóvenes sobresalientes para el régimen que ocupaban candidaturas en la política provincial, ${ }^{12}$ pero aclaraba que no había que confundir al enemigo como en 1973, ya que en ese año, el PJ había sido derrotado por el MPN cuando se presentó como el verdadero peronismo en Neuquén. Efectivizadas las elecciones internas, Massei triunfó en la presidencia del partido y como candidato a gobernador, con el apoyo de organizaciones sociales vinculadas a barrios, actividades, viviendas y una agrupación de abogados. Contaba, además, con representantes en la mayoría de las localidades neuquinas y su compañero de fórmula era el dirigente gremial Luis Novoa.

El PJ de Neuquén, similar a otros distritos del país, no registra discusiones acerca de qué entendía por ortodoxia y renovación, solo se observa la emergencia de un sector dirigente más joven, que no tenía el peso del conflicto de los años setenta; la mayoría provenía de la militancia en La Tendencia, la JUP, la dirigencia gremial y muy pocos del Peronismo Revolucionario. Reproducían en este distrito -mayoritariamente- las disidencias, las enunciaciones y las estrategias nacionales -aunque algunas de las críticas y tácticas fueron aplicadas de modo diferente en Neuquén, porque aquí el principal contrincante no era la UCR, sino el MPN-.

\section{Las elecciones y los ganadores}

Cuando se produjeron las elecciones de 1983,13 triunfó nuevamente en la Gobernación el MPN, con mayoría en la Cámara de Diputados. Las elecciones en Neuquén mostraron dos ganadores claros decididos por la ciudadanía: Alfonsín-Martínez y Sapag-Forni, echando por tierra análisis previos, a pesar que la provincia había duplicado su población en los últimos diez años en base a las corrientes migratorias internas. El emepenismo continuó siendo el eje alrededor del cual giraba el panorama político. Si bien la figura de Alfonsín eclipsó las elecciones en Neuquén y el Radicalismo luchó palmo a palmo con el Justicialismo con cortes de boleta, el primero logró ubicar 7 electores para presidente.

\footnotetext{
11 "Acto de clausura del PJ", Río Negro, 25/10/83.

12 Se refería a Jorge Sobisch, uno de los seleccionados como representante de los jóvenes destacados neuquinos en la visita del Gral Jorge Videla a la región y candidato a intendente por el MPN en la ciudad de Neuquén en las elecciones de 1983, en "Acto del PJ en Neuquén", Río Negro, 09/10/1983.

${ }^{13}$ Sobre un total de 112.550 total de votantes, participaron el $86.60 \%$ de electores en condiciones de votar.El MPN obtuvo el $55.26 \%$ de votos.
} 
Se observó una diferencia de $40 \%$ de votos que separaba al partido provincial para gobernador y en electores a presidente. Es decir, los cortes de boleta expresaban una ciudadanía con intención -dada la fórmula existente- de no delegar el derecho a su rol de electores; incluso, llamó la atención que el candidato del PJ, Massei, tenía más votos para gobernador que los que obtuvieron los diputados provinciales, los nacionales $y$ la fórmula presidencial; ${ }^{14}$ contaba con el apoyo de la mayoría de los gremios de Neuquén, excepto el Centro Empleados de Comercio, SMATA, el Sindicato de la industria maderera y Petroleros Privados. ${ }^{15}$ En la UCR había sucedido al revés, había más votos para diputados provinciales que para gobernador y mucha presencia de las 'boletas blancas' (Alfonsín-Martínez).

El PJ logró el 22\% de los votos, igual porcentaje que la UCR, pero ingresó a la legislatura provincial con cinco sufragios más que la primera. En realidad, en los comicios de 1983 se produjo una importante polémica: la UCR y el PJ habían empatado de manera increíble en legisladores. La impugnación de una mesa de una escuela le posibilitó al PJ obtener el triunfo. ${ }^{16}$ Así se presentó un oficialismo sobre-representado y una oposición sub representada al ingresar solo un partido por la misma. Recién la renovación de las cámaras en 1987, permitió el ingreso de la UCR con un 29\%, diez puntos más que el PJ (Vaccarisi y Campos, 2010). Por el sistema unicameral, sin renovación parcial, con sistema de mayoría y minoría en la Cámara de Diputados, el partido ganador se convertía en el centro de la iniciativa y decisión. La segunda fuerza encontraba obstáculos para ejercer su función de fiscalizadora, dado que con ese esquema la Legislatura no controlaba al ejecutivo, sino a la oposición (Favaro y Arias Bucciarelli, 1999).

Desde la década de 1980, Massei ejercía liderazgo en el PJ neuquino; sin padrinos, tenía como interlocutores a Cafiero y Grosso y los vaivenes de los congresos nacionales justicialistas influyeron en las decisiones de este sector interno de renovadores en Neuquén. A diferencia del resto de las provincias estudiadas (Ferrari y Mellado, 2016) si bien les interesaba recuperar el espacio de poder emergía hacia adentro y afuera del partido, un debate de ideas que giraba alrededor de la situación del justicialismo nacional porque consideraban carecía de consenso, credibilidad y confianza. En sintonía con el orden nacional, afirmaban que el diálogo entre el presidente de la Nación y la cúpula partidaria peronista no podía estar supeditada a la presencia en Argentina de María Estela Martínez de Perón. En este orden, Massei intentó -con magros resultadosinstalar una agenda de temas y problemas a resolver en Neuquén y en la

\footnotetext{
14 "Elecciones generales", Revista Calf, 03/1983.

15 T.O., O.M, 22/08/18.

${ }^{16}$ Héctor Castillo (que fue director de prensa del gobernador), dijo que Sapag había enviado a votar a sus afiliados por el PJ en la elección complementaria del 20 de noviembre de 1983, en el marco de un acuerdo realizado entre las partes.
} 
Patagonia. En coincidencia con el resto de los distritos, la conducción y algunos dirigentes del PJ, coincidían en la demanda de reforma de la Carta Orgánica del peronismo a nivel nacional con el objetivo de permitir la selección de candidatos y autoridades partidarias a través del voto directo de los afiliados.

En la provincia, además se formó una comisión parlamentaria, conducente a re analizar la cuestión de los DD.HH. Así, la Legislatura aprobó por unanimidad en marzo de 1984 la constitución de la Comisión Especial Legislativa de los Derechos Humanos (de cinco diputados), presidida por José Sifuentes (MPN) y como secretario designó a Oscar Montórfano (PJ); tenían como objetivo recepcionar las denuncias planteadas por familiares frente a la violación a los DD.HH y los desaparecidos. ${ }^{17}$ Asimismo, los diputados peronistas neuquinos constituyeron el Bloque de Legisladores Provinciales y Territoriales Justicialistas de la Patagonia (1984), con representantes de las provincias respectivas en el marco del Congreso Nacional. En el pronunciamiento de conformación, los legisladores exhortaron al resto de los legisladores nacionales asumir una actitud similar, convocando a los diputados patagónicos aunar esfuerzos y proyectos; se planteó la necesidad de revalorizar el concepto federalismo, para lo cual se propuso un nuevo Pacto Federal. Este tema era de suma importancia porque la disputa a nivel local era con el MPN y ese entramado cuestionaba a los partidos (en esta coyuntura no solo al PJ sino también a la UCR), ${ }^{18}$ porque el MPN se consideraba representante del federalismo y el federalismo lo expresaba el MPN. Ya en la campaña había dicho que si para el PJ hablar de federalismo era hablar de Nación, para el MPN, el federalismo se entendía en confrontar con la Nación, porque en el nuevo contexto político, la dicotomía no era el verdadero peronismo, sino los neuquinos vs Nación para defender los recursos provinciales, ya que aquella era una entidad 'ajena' que no respectaba el federalismo y capturaba el gas y el petróleo de los neuquinos. Sin desconcer su origen, los dirigentes emepenistas continuaban marcando su trayectoria e identidad, su programa de políticas sociales y su defensa de los intereses de la provincia, hechos que influyeron en los éxitos y fracasos de la renovación del peronismo (Rafart, 2016: 39).

\section{El desenlace: los que se fueron}

A medida que se realizaban los congresos nacionales del justicialismo, se reafirmaba la idea de un grupo pequeño del PJ de Neuquén sobre la necesidad

\footnotetext{
${ }^{17}$ Contaba con el apoyo y colaboración del Obispo De Nevares, en "Desapariciones y violación a los DD.HH", Revista La Trastienda, 16/03/1984.

${ }^{18}$ La UCR planteó una revisión del federalismo, a través del aporte de uno de sus dirigentes, Eduardo Del Río, quien afirmaba que "El federalismo debía ser participativo, coparticipando decisiones desde la Nación a las provincias y de estas a los municipios; por todo esto, consideraba obsoleta la propuesta del MPN, en Río Negro, 01/09/1985.
} 
de renovación del peronismo y que el hecho los alejaría del conjunto que continuaba representada por la línea política sindical ortodoxa central; en el ámbito local de Nievas y Camacho González. La tarea de esta línea interna que se venía pergeñando, estuvo acompañada de múltiples dificultades porque en Neuquén el único peronismo con historia era el MPN y el peronismo sólo podría ser "renovación" (Palermo, 1988: 82). De todos modos, en poco tiempo, el PJ había crecido en la provincia un $25 \%$, la UCR en $16 \%$ y el MPN había retrocedido en un 13\%; los "renovadores neuquinos" habían participado de la mayoría de los congresos nacionales, menos el de Tucumán donde se realizó el acuerdo de Menen con algunos integrantes de la dirigencia renovadora central y sectores sindicales.

Esta situación hizo que el 9 de noviembre de $1986,{ }^{19}$ más de cincuenta militantes del peronismo neuquino, ${ }^{20}$ encabezados por el entonces presidente del PJ, Oscar Massei, decidieran romper con el partido y conformar uno nuevo al que llamaron Justicia, Democracia y Participación (JDP). ${ }^{21}$ Los firmantes de El documento en el que se anunciaba la constitución de un partido provincial demás de Massei- estaban Luis Pereyra, David Lugones, Raúl Radonich, ${ }^{22}$ Rodolfo Caso, Hugo Villarreal, Raúl Sandoval, Oscar Montórfano, Jorge Wálter, Juan José Servidio y Bernardo Gavernet. Decía entre otras cuestiones, que “El pueblo ya se fue. Entre las estructuras vacías de contenido, optamos por el pueblo. Por eso, como militantes renunciamos a los cargos partidarios y a nuestras afiliaciones al partido Justicialista" ${ }^{23}$ En el documento de ruptura se formulaban duras críticas a la conducción nacional del peronismo, resolución tomada -además- en el marco de la llegada del "veedor" del Consejo Superior Justicialista, Alberto Melón. ${ }^{24}$ Las reuniones de estos renovadores se replicaron en la provincia y localidades de la misma y Massei contó rápidamente con

\footnotetext{
${ }^{19}$ La mayoría de los integrantes del nuevo partido, participó de una reunión en una chacra en Cinco Saltos (Río Negro), de propiedad de la familia Sandoval, el 9 de noviembre de 1986.

${ }^{20}$ El PJ de Neuquén tenía en 1983, solo el 5\% de los 130 mil electores provinciales.

${ }^{21}$ Se decía que la sigla significaba Juan Domingo Perón. T.O., O. M, 19/05/18.

22 Tanto Raúl Radonich como David Lugones venían de la militancia universitaria en la UNLPlata, en la JP o la JUP. El primero de la carrera de Sicología y el segundo de Medicina. Solo el segundo fue detenido en el lugar donde estudiaba; mientras que Radonich en Neuquén y en dos oportunidades. Ambos estuvieron en el centro clandestino de detención La Escuelita de la provincia. Radonich había participado durante sus estudios secundarios en el Colegio Don Bosco de Neuquén, en la Casa de la Juventud, que reproducía modelos de militancia de los jóvenes en tareas sociales-barriales, implementados con éxito en Colombia. T.O, R.R, 24/07/18 y D.L. 01/08/2018; 02/08/2018.

${ }_{23}$ "El Documento", Río Negro, 10/11/1986.

${ }^{24}$ Melón- ligado de Guardia de Hierro- fue designado por Saadi,Triaca y Rodríguez Saa como "veedor" en el PJ de Neuquén, con amplias facultades estatutarias. Los motivos para justificar el hecho, fueron las denuncias anónimas que imputaba al PJ local por falta de registros de aportes, desactualización del padrón, desmovilización de unidades básicas y por la conducta asumida por la autoridad partidaria frente a la visita de Ubaldini, en "Entre turcos anda el juego", Río Negro, 25/10/1986.
} 
abundante y variada adhesión. El nuevo partido y su conducción evaluaba el armado de un frente con perspectivas a la elección a Gobernador de 1987; aspiraba además en colaborar en la sustitución de la conducción nacional elegida en el congreso de Santa Rosa. Sin embargo, la ruptura planteaba contradicciones en la renovación neuquina, porque algunos dirigentes y militantes consideraban que el problema era Iglesias y Lorenzo Miguel y "la batalla debía darse dentro del peronismo". ${ }^{25}$

Cuando Massei rompió con la estructura de su partido en Neuquén y se creó el JDP, se esperaba que, con diferencias de días, ocurriera algo similar en otras provincias. Las internas nacionales se llevaron a cabo y si bien los renovadores marcaron diferencias, se produjeron las tradicionales alianzas del PJ y la proyección nacional quedó sin efectivizarse. La idea del Frente -con la DC y el PI- la propuesta de estos renovadores, se mantuvo como núcleo básico de ideas del sector masseísta, porque la consideraba como la nueva forma de hacer política que implicaba para Neuquén “...continuar y superar todo lo bueno que tiene esta provincia", ${ }^{26}$ a partir de la participación no solo en una situación pre electoral sino como un hecho cotidiano, sin convertirse en un simbolismo y con el objetivo de disminuir el autoritarismo.

Formó un bloque propio en la Cámara de Diputados provincial con Montórfano y Luisa Pérez (dos sobre un total de diez legisladore ${ }^{27}$ ), circunstancia que obligó realizar varias reuniones a los peronistas en la Legislatura, por considerar a la situación como confusa. Sobre 17 integrantes de la conducción partidaria local, 8 renunciaron a su afiliación y pasaron a integrar el nuevo partido: JDP. La ruptura la dicidió el grupo que había triunfado ampliamente con Massei (Lista Celeste) en la interna para la renovación a cargos partidarios -en abril de 1985- frente al otro sector (Lista Verde) en la que se destacaba la figura de Oscar Parrilli. ${ }^{28}$ Los integrantes del nuevo partido -que contaba con el presidente del mismo y el del congreso provincial, Raúl Cabezas- decidieron desafiliarse colectivamente del PJ, tenían apoyo de sectores sociales y políticos de la provincia, fundamentalmente, del interior neuquino.

Las diferencias entre esta línea interna "renovadora" y la otra que si bien proclamaba su adhesión a la renovación -mantenía relación con la ortodoxia nacional- habían quedado plasmadas con el triunfo en la interna de la Lista Celeste por parte del sector liderado por Massei. Surgieron más conflictos con el intento de la JDP de cambiar la presidencia del bloque justicialista en la legislatura neuquina: había interés en reemplazar a Alé Rada (PJ) por

\footnotetext{
25 T.O. Carnaghi,09/12/2012

26 "Una nueva forma de hacer política", Revista Calf, 08/07/1987.

${ }^{27}$ Los diez legisladores habían ingresado en 1983 a la Legislatura de Neuquén. Quedaron dos con la JDP y ocho en el PJ.

${ }^{28}$ T.O., R.R, 24/07/18.
} 
Montórfano (JDP). ${ }^{29}$ El nuevo escenario rompió el delicado equilibrio que se pretendió mantener desde 1983, entre los que ya se delineaban como dos sectores en el partido. Recordemos que la ruptura se produjo, luego que en las elecciones de legisladores nacionales (1985), fuera elegido Massei como diputado por el PJ, en el contexto en que la nueva propuesta renovadora tenían pocas posibilidades en Neuquén porque quedaba encerrada entre las figuras convocantes de Alfonsín y el caudillo del MPN, Felipe Sapag.

Es necesario subrayar que habían variadas razones por las cuales se producía la ruptura en el PJ de Neuquén. La derrota de 1983, el triunfo del Radicalismo en el Referendum del Beagle (25/11/1984) por el papel que le cupo a Saadi (PJ) frente a Caputo (UCR), las elecciones de legisladores (03/11/85) y la Ley de Reordenamiento Sindical (15/03/1984) mostraban los traspiés del peronismo, sus internas y reflejaban los desacuerdos con la Conducción Nacional del PJ. Esta situación fue generalizada en la mayoría de la renovación de las provincias. Había algunas coincidencias con el gobierno nacional especialmente las vinculadas al rol de los partidos para la consolidación de la democracia; pero el mantenimiento de la política ortodoxa y sin renovación del PJ, sumaba cuestiones que llevaron al armado de esta línea interna liderada por Massei y presentar su renuncia al PJ de Neuquén ${ }^{30}$. Algunas razones se vinculaban a su acuerdo por la consulta en el tema del Beagle -a contramano de lo que había decidido la mayoría de la dirigencia local- y compartida con el Secretario General de la CGT de la provincia, Cabezas y otros sectores de la militancia.

La situación política se complejizaba más, cuando los encuentros y acuerdos de los justicialistas en el Senado reafirmaron la idea y acción del PJLorenzo Miguel, de intentar reingresar el MPN al peronismo, circunstancia que fue ratificada por Nievas, quien había sido interventor del partido en Neuquén. Los comentarios fueron desmentidos por Sapag, subrayando que el entramado local era independiente, equidistante del Peronismo, del Radicalismo y de cualquier otra fuerza. Para reafirmar esta idea, Sapag apoyaba el proyecto radical de la Reforma del Código de Justicia Militar y decía que si bien en el campo gremial había un trabajo conjunto con el PJ, en el terreno político había bastante para discutir. ${ }^{31}$

Respecto del acercamiento entre el PJ-MPN, dice Massei

\footnotetext{
29 “¿Oscar Montórfano por Alé Rada?”, Río Negro, 27/04/85.

${ }^{30}$ Fue rechazada en el partido. Massei en una carta a sus compañeros del PJ, consideraba que "... la quietud del partido, son consecuencia directa de la falta de dirección", de la que se sentía responsable, en "Renuncia de Massei como Presidente del Consejo PJ de Neuquén", Archivo Personal del Dr Massei, 08/03/1984.

31 “En voz baja”, Revista La Trastienda, 22/10/1986 y "El MPN no ingresará al PJ", Río Negro, 25/10/1986.
} 
“Con el MPN hubo relaciones, en especial bajo mi presidencia [se refiere al PJ]. [...] antes de las elecciones a diputados de 1985, me convoca el presidente del PJ nacional, Vicente Saadi senador nacional por Catamarca- y me dice que deberíamos construir un frente con el MPN en Neuquén [...] y que nos íbamos a reunir con Elías Sapag [senador por Neuquén] [...] concurro a la reunión y me reciben los dos senadores, Elías me hace la propuesta. Le expresé que consultaría mis compañeros del PJ y me dice que hable con Felipe Sapag..." [...] "De regreso a Neuquén me reuno con la conducción del PJ, trasmito la propuesta que tuvo acogimiento, porque era como volver al PJ que eran los orígenes del MPN, aunque sea en un frente. Me piden que vaya solo a reunirme con Felipe....me recibe.....una charla de más de una hora.....me dijo rotundamente que no y que.....son manejos inconsultos de su hermano... y vos tenés futuro...." 32

Recordemos que el último interventor del PJ, Melón, ingresó acompañado por el primer fiscalizador Nievas, quien había sido derrotado por el sector de Massei y tenía instrucciones, según sus propias afirmaciones, de "limpiar de zurdos" al PJ y continuar analizando la conveniencia de una alianza con el MPN. ${ }^{33}$ Había sido muy categórico en la necesidad de una alianza frentista con el MPN, ya que "Felipe Sapag era parte indivisible del MPN". Nievas decía que Sapag -a diferencia de Massei con el JDP- cuando lanzó el MPN, reflejó la ineludible necesidad de sortear la proscripción del peronismo, como hicieron en su momento Tres Banderas, el Movimiento Popular Salteño y la Unión Popular. ${ }^{34}$

En definitiva, se presentaba una situación compleja, ya que en las elecciones a legisladores nacionales del 6 de septiembre 1985 había sido elegido Massei; un año después su sector rompió con el PJ y formó el JDP, retirándose del bloque de diputados provinciales y del resto del justicialismo. El nuevo contexto, derivó en denuncias y en la solicitud de renuncia a Massei a sus cargos que mantuvo hasta 1987, cuando al disputar la gobernación -y obtener escasos votos- declinó la banca en el congreso nacional. Lo debía reemplazar, un dirigente del partido, Juan José Servidio (yerno de Cafiero), quien no aceptó, accediendo Ernesto Ramírez (dirigente sindical del SUPE). ${ }^{35}$

\footnotetext{
32 T.O., O.M,19/05/2018.

33 "Unos se fueron, otros se quedaron y otros volvieron", Río Negro,16/11/1986.

${ }^{34}$ Río Negro, 25/11/1986.

35 T.O., O.M.,19/05/2018. Massei afirmaba que solo se quedaría si se lo ratificaba en la elección para Gobernador (1987). Al ser derrotado por el MPN, presentó su renuncia en el marco de tensiones en el partido, por la movilización de dirigentes y militantes, en "La renuncia de Massei", Río Negro, 15/09/1987.
} 
Oscar Massei, el dirigente carismático que nucleaba al grupo escindido, explicaba en 1987, que el problema en el peronismo de Neuquén, no era simplemente un tema metodológico, era una cuestión de conducción, organización y perfil ideológico. El asunto de quien era el fundador de la renovación o principal referente de la misma no era la cuestión porque se discutía y disputaba en los congresos del PJ nacional -sino la definición del "perfil ideológico del peronismo"-. Señalaba que no se definía un proyecto político, se caía en internismos y en la disputa por ocupar áreas de poder. Ratificaba que el espacio que la renovación estaba ganando, en parte, era producto de la política del Radicalismo, porque el Peronismo no lograba precisar temas fundamentales, dado que la discusión -en la que no lograban acuerdos- pasaba por "... saber si esta sociedad ha cambiado en los últimos tres años o no, si la estructura de la sociedad es la misma que hace cuarenta años o tiene otros componentes". Había una cuestión que el peronismo debía recomponer y era "la concepción movimientista que debía recuperar el peronismo, la cual se ha olvidado para caer en un manejo directamente de un partidocráctico liberal, a través de tener un partido ordenado, doméstico". [...] "Esta es una cosa que el peronismo de la renovación no marca fundamentalmente" (Gordillo y Lavagno, 1987: 185-193).

Este análisis no ofrecía muchas coincidencias en el resto del PJ neuquino, como también en el amplio sector de los propios renovadores de los espacios centrales; no obstante, los masseístas -cuyas voces pertenecían a una militancia intelectual y política con circulación y adhesión en una parte del partidopretendían descongelar los viejos conflictos y tensiones que no habían logrado saldarse en años anteriores (entre otros, los años setenta, la dictadura, los DD.HH). De todos modos, faltaba ampliar bases propias y otro perfil para seducir al electorado neuquino, no solo al emepenista que dividía su voto en nacional y local, sino también al independiente. A diferencia de los principales dirigentes nacionales, el masseismo priorizó su lucha por la idea más que por el espacio de poder, lo cual mostró en clave subnacional, que la experiencia de ruptura neuquina fue compleja y discontinua y el proyecto tuvo obstáculos para continuar, más aún en el contexto de la recomposición del PJ nacional.

\section{Otros se quedaron y algunos volvieron}

Entre los que permancieron en el PJ de Neuquén, se observaban cinco sectores: uno que rápidamente adhirió a Nievas (primer interventor) ligado a Lorenzo Miguel, un segundo grupo vinculado a las 62 Organizaciones -que contaba con el apoyo provincial de Enrique Esperón- que tenía su anclaje nacional en el dirigente petrolero Diego Ibáñez. Luego estaban los denominados "quedantistas" -los que tenían mayor número de adhesiones- liderados por el vicepresidente del bloque de diputados provinciales del PJ, Oscar Parrilli, quien 
buscó el respaldo de la conducción nacional renovadora ante la fractura, sin cortar los vínculos con el resto del PJ nacional ni con el Consejo Nacional Justicialista. Por último, el Peronismo Revolucionario de Lava y Vilche, cercano a Saadi y el grupo Federalismo y Liberación que adhería a Carlos Menen.

El PJ de Neuquén con los que se quedaron, planteaba como objetivo principal que se debía ganar la Gobernación en 1987 y triunfar en las elecciones nacionales de 1989. A pesar de ruptura, no se descartaba la idea que podían ir como JDP o como PJ y no importaba si con Cafiero o con Menen; la cuestión era ser gobierno y tener poder. De forma que en las internas de mayo de 1988 en el Justicialismo neuquino, se conformaron tres sectores: la lista Celeste y Blanca del Peronismo para la Victoria, con Parrilli, Duzdevich y Kogan que apoyaban a Cafiero en el orden nacional y provincial, con Oscar Parrilli como candidato al Consejo Provincial; la Verde de Lealtad y Federalismo-Menem Presidente, con Carlos Vilche y La Negro-Punzó de Afirmación Peronista con Horacio Lava. Vilche y Lava adscribieron a Menem y Parrilli a Cafiero. Hubo una estrategia de las dos últimas listas mencionadas, por el accionar de Daniel Baum, que permitió la victoria de Menen. La situación obligó a varios dirigentes, entre otros, Parrilli y Enrique Masés, llevar a cabo una reunión con Menem para aclarar la situación y también, reordenar el partido ante el nuevo contexto. ${ }^{36}$ En Neuquén, como en la mayoría de los distritos había sido derrotada la fórmula que apoyaba a Cafiero.

Se visualizaba una contradicción entre el hecho de apoyar a Menen para las internas de julio de ese año, pero compartir lista en la provincia con los partidarios de Cafiero, centrados en que el PJ debía ganar las elecciones. La prensa de la época, informaba en la región sobre los resultados electorales de julio de 1988 en la provincia, alegando que “...a muchos dejó perplejos que en una provincia donde el gobernador riojano ganó con tanta claridad, fuera Cafiero el que recibiera el apoyo del electorado para convertirse en titular del consejo partidario neuquino". ${ }^{37}$ En Neuquén, Menem-Duhalde obtuvo el $82.89 \%$ de votos (4224 votos) y Cafiero-de la Sota, $17.11 \%$ (872 votos). ${ }^{38}$ Luego de las mediaciones y acuerdos partidarios, Parrilli se instaló en el lugar que otrora ocupara Massei, momento en que comenzó a gestar la idea de postularse a gobernador, voluntad compartida en el PJ y reiteradamente ejecutada. ${ }^{39}$ Por último, respecto del JDP -que no participó en esta contienda- se manifestaba renuente a apoyar a Carlos Menem y conservaba la idea de un Frente para las

\footnotetext{
36 T.O.,E.M., 17/12/2018.

37 "Un cafierista para una provincia de Menem", Revista Calf, 07 /08 /1988

${ }^{38}$ Así Menem-Duhalde, obtuvieron 3.518 votos, contra 755 de Cafiero-De la Sota, mientras que en el orden provincial para el Consejo Partidario, triunfó Parrilli (Celeste y Blanca) con 1880 votos. La estrategia estaba encabezada por Aldo Duzdevich de la Celeste y Blanca y tuvo escasa participación de los afiliados.

${ }^{39}$ Río Negro, 21/05/1989.
} 
elecciones de 1989 con el PI-DC, contemplando la posible candidatura de Carlos Auyero $^{40}$ hecho que no se concretó.

En el contexto de la democratización del PJ, inicialmente la mayoría de los peronistas neuquinos se proclamaban renovadores. Pero la renovación, en general, tanto nacional como neuquina, tenía muchos matices. En el caso del sector renovador que creó la JDP, mantuvo la idea del Frente, el concepto de unidad con algunos pequeños partidos, en particular, con dirigentes con los cuales -varios de sus dirigentes- habían sostenido relación durante la dictadura, por temas, entre otros, como los DD.HH. ${ }^{41}$ Dentro del heterogéneo grupo peronista neuquino el sector masseista pretendía no solo democratizar sino renovar al partido, con un liderazgo, enfrentando el aparato verticalista con respaldo de las bases, aunque surgían ciertas objecciones "por los nombres que aparecían..." (sic). ${ }^{42}$ Por un lado, este sector, sin perder la autonomía, no negociaba con las autoridades nacionales del partido -algo corriente luego de las internas-, por otro, el grupo mayoritario -venía desde la elección nacional de 1983- que se movía entre el contexto local y el nacional, negociaba dentro y fuera de la provincia e imponía la disciplina partidaria. Este fue el sector que quedó y que condujo el Justicialismo en Neuquén.

La inserción nacional del JDP se había postergado, aunque Massei se encargaba de subrayar que el partido que presidía era peronista, no ya renovador, por supuesto, ya que los hechos habían demostrado el abandono de la idea o la imposibilidad de renovar como lo pensaba. Afimaba que para 1989 no había alternativas, sino solo opciones en el mercado electoral y no descartaba, nuevamente, la posibilidad de un frente con el PJ en adelante, siempre que incluyera los partidos de izquierda. ${ }^{43}$ De este modo, la mayoría de los dirigentes masseistas solo reaparecieron en la vida política en determinadas coyunturas electorales y regresaron, mientras tanto, a su actividad privada.

\section{Reflexiones finales}

El grupo renovador peronista nacional se convirtió en el actor que dinamizó el justicialismo durante más de dos años -los de su crecimiento- desde mediados de 1985 hasta las elecciones de septiembre de 1987, disputando el gobierno y el poder en el orden en dos frentes: hacia adentro, para intentar capturar la

\footnotetext{
40 "Hoy vemos algo nuevo", Río Negro, 18/09/88,

${ }^{41}$ De allí que esta línea interna se conservó, en primer lugar, en las elecciones provinciales para Gobernador de 1987, en las que se conformó un frente con la Democracia Cristina y el Partido Intransigente, aunque sin éxito, continuó frente a las políticas neoliberales del gobierno de Menen y "con el grupo de los 8 nutrieron el Modejuso, el Fredejuso y posteriormente el Frente Grande y La Alianza (Ferrari et al, 2016: 9-34).

42 "Neuquén. Posibilidad de acuerdo a nuestra óptica no suena bien dentro del movimiento", Revista Aquí nosotros,10/10/1983.

${ }^{43}$ Río Negro, 14/07/1988.
} 
dirección del PJ y hacia afuera, al Radicalismo de Alfonsín, por la representación política. En Neuquén, pugnó con el MPN, partido hegemónico en el sistema de partidos de la provincia desde 1963, con el que disputaba el mismo espacio político.

Los renovadores del JDP en Neuquén, respecto del PJ gestionaron una propuesta más democratizante e integradora y sus dirigentes mantuvieron un estilo y una crítica positiva al gobierno de la UCR, incluso en varias oportunidades tuvieron importantes coincidiencias. Consideraban que para ser gobierno se debía entender no solo el nuevo escenario nacional, sino en particular, el subnacional -porque no eran iguales- y reforzar la vocación de poder para constituirse en alternartiva al MPN. Para ello, era necesario salir de la crisis que atravesaban por la tensión de identidad que llevó a la fragmentación del PJ, aun en provincias en las que había triunfado en 1983. Coincidían en el cuestionamiento generalizado a la conducción oficial del partido antes y durante el proceso electoral; aunque las ideas de la dirigencia renovadora masseísta pretendía darle cuerpo doctrinario a una corriente que aspiraba tuviera un sentido superador en este espacio subnacional, tanto del PJ como del propio emepenismo. En este sentido, la idea central era que en Neuquén se derrotaba al MPN si se disponía de un frente, que a diferencia de una alianza o coalición, adquiría una dimensión social más amplia, porque incluía propuestas de las fuerzas que concurrían en el mismo.

Si bien coincidían con el resto de los renovadores que el Peronismo debía ser abierto, flexible y participativo, sin aparatos, la estrategia que proponían era diferente. La mayoría de los masseístas solo regresaron al PJ en momentos en que emergía más renovado, el propio Massei solo con La Alianza. Por ello, en determinadas instancias electorales acordaron con la DC y el PI, pero estas fuerzas solo eran atractivas en un departamento tan urbanizado como el Confluencia donde se encuentra la capital y residen la mayoría de los sectores medios. Por lo tanto, no eran entramados gravitantes para reclutar elencos políticos en el marco de la tensión en términos identitarios y de las prácticas sociales que emergían en el Peronismo.

En este marco, coincidimos con Palermo cuando afirma que el Frente organizó en Neuquén, lo que no sucedió en otras provincias “...desgajar (una parte de) la izquierda peronista e integrarla a un frente amplio-democrático y conformar con ese perfil una expresión política significativa" (Palermo, 1988: 88-89). En definitiva, pudieron competir con el MPN, incluso con el mismo PJ, pero no lograron acceder más que a cargos legislativos en la provincia y en la Nación. Fueron un grupo pequeño, de corta vida, que buscó una línea de continuidad en una renovación diferente en el partido; con una interesante diversidad de origen y trayectorias por las experiencias forjadas en la militancia social,barrial y universitaria; tuvieron pluralidad ideológica y aunaron de algún modo, una generación intermedia, la de los años 1970 en la provincia. 
Había que tener en cuenta, respecto del MPN, que el partido venía triunfando desde 1963 y tenía estructuras partidarias con el volumen y la densidad política necesaria -por los recursos financieros, simbólicos y organizacionales- para constituirse en la fuerza convocante en cada elección provincial. El empleo público era clave en la arena electoral y alineaba a buena parte de los dirigentes políticos e intendentes con lo cual en cada coyuntura, se visibilizaba la construcción territorial que permitía dar cuenta de la continuidad del oficialismo.

Con esta estructura tenía que competir la JDP -como otro partido provincial- por una parte, interpelando desde otros discursos y prácticas a la heterogénea ciudadanía neuquina, por otra, sortear a Felipe Sapag como referente nacional de Neuquén. Con el MPN se hacía difícil para la nueva fuerza partidaria "atrincherarse provincialmente" frente al otro peronismo y tener un lugar en la política con una propuesta provincialista.

\section{Testimonios Orales}

Testimonio Oral de Oscar Massei, Neuquén, 19/05/18; 30/05/18; 25/06/18; 14/07/18; 22/07/18 y 13/08/2018

Testimonio Oral de Raúl Radonich, Neuquén, 24/07/18

Testimonio Oral de David Lugones, Neuquén, 01/08/2018; 2/08/2018.

Testimonio Oral de Enrique Masés, 17/12/2018 y 27/12/2018.

Entrevista online a Guillermo Carnaghi,09/12/2012

\section{Bibliografía citada}

Arias Bucciarelli, Mario (2011). "Los partidos políticos frente al 'terrorismo de estado'. Un estudio de caso: la campaña electoral de 1983 en Neuquén" en Revista Estudios, CEA/UNC, Córdoba, pp.101-119.

Azconegui, María Cecilia (2019). "Política y dictadura en Neuquén. La APDH y la formación de jóvenes, 1980/81", en Revista Izquierdas, Chile, núm. 49.

Basso, Germán (2011). “La renovación peronista en cuestión: una aproximación a la experiencia del peronismo durante la década del '80", en Antítesis, Buenos Aires, núm. 8, pp.801-825.

Brachetta, María Teresa (2016). "La Renovación peronista: una agenda enriquecida", en Ferrari, Marcela y Mellado, Virginia (comps.) La Renovación Peronista. Organización partidaria, liderazgos y dirigentes, 1983-1991, Buenos Aires: Editorial de la Universidad Nacional de Tres de Febrero, pp. 299-322. 
Camino Vela, Francisco y Rafart, Gabriel (2012). La política democrática en la Patagonia: predominios partidarios en las provincias de Neuquén y Río Negro, Río Negro: PubliFadecs.

Camino Vela, Francisco y Rafart, Gabriel (2014). “La Patagonia en la transición: el '83 y las tres décadas de democracia electoral", ponencia presentada en la VI Jornada de Historia de la Patagonia, Universidad Nacional de La Pampa.

Castellani, Ana (2004). “Gestión económica liberal-corporativa y transformaciones en el interior de los grandes agentes económicos de la Argentina durante la última dictadura militar", en Pucciarelli, Alfredo (coord.) Empresarios, tecnócratas y militares. La trama corporativa de la última dictadura, Buenos Aires: Siglo XXI, pp.173-218.

Delgado, Soledad (2003). “'El otro partido': algunas consideraciones acerca del Radicalismo (1983-1989)", ponencia presentada en el VI Congreso de Ciencia Política, Universidad Nacional de Rosario.

Favaro, Orietta (2017a). “Claves para comprender la historia de Neuquén: estado y partido", en Duimich, Laura, García Gualda, Suyai y Sartino, Julieta (eds.) Neuquén. 6020 10. Un libro de teoría política, Río Negro: PubliFadecs, pp.115-142.

Favaro, Orietta (2017b). "Neuquén (Argentina) en clave política. Estado y partido, 1961-1991", en Estudios Sociales del Estado, Buenos Aires, núm. 6, pp.191-217.

Favaro, Orietta y Arias Bucciarelli, Mario (1999). “El sistema político neuquino. Vocación hegemónica y política faccional en el partido gobernante", en Favaro, Orietta (ed.) Neuquén. La construcción de un orden estatal, Cehepyc/Clacso, Neuquén: Universidad Nacional del Comahue, pp.253-267.

Favaro, Orietta y Iuorno, Graciela (2013). La trama al revés en años de cambio, Río Negro: PubliFadecs.

Ferrari, Marcela (2017). "La política frentista del peronismo renovador durante los años ochenta. Las coaliciones de izquierda", en Cuadernos del Claeh, Uruguay, núm. 105, pp. 9-34.

Ferrari, Marcela y Mellado, Virginia (comps.) (2016). La Renovación Peronista. Organización partidaria, liderazgos y dirigentes, 1983-1991, Buenos Aires: Editorial de la Universidad Nacional de Tres de Febrero.

Garategaray, Martina (2010). “Peronistas en transición. El proyecto político ideológico en la revista Unidos (1983-1991)", en Nuevo Mundo Mundos Nuevos [En línea https://journals.openedition.org/nuevomundo/60126].

Garategaray, Martina (2013). “Entre Perón y Alfonsín: Notas sobre la Renovación peronista (1983-1988)”, en Temas y Debates, Rosario, núm. 25. 
Gordillo, Marta y Lavagno,Víctor (1987). Los hombres de Perón. El peronismo renovador, Buenos Aires: Puntosur editores.

Iuorno, Graciela (2016). "La renovación no alcanzó para la alternancia en Río Negro (década del ochenta)", ponencia presentada en $V$ Congreso de Estudios sobre Peronismo, Universidad Nacional del Noreste, Resistencia.

Iuorno, Graciela et al (2017). "Su primer naufragio. El peronismo rionegrino en 1983", en Moroni, Marisa et al (coord.) Reconfiguraciones identitarias. Miradas de la Historia Argentina desde la Patagonia, Instituto de Estudios Sociohistóricos, Santa Rosa: Editorial Universidad Nacional de La Pampa, pp.176-185.

Levitsky, Steven (2003). La transformación del justicialismo. Del partido sindical al partido clientelista, 1983-1999, Buenos Aires: Siglo XXI, pp. 128-145.

Macor, Darío y Tcach, César (2003). La invención del peronismo en el interior del país, Santa Fe: Universidad Nacional del Litoral.

Palermo, Vicente (1988). Neuquén: la creación de una sociedad, CEAL, Buenos Aires: Colección Biblioteca Política Argentina, núm. 212.

Rafart, Gabriel (2016). “El '83': sindicatos y peronismo federal en Río Negro y Neuquén", en Revista de la Facultad, Universidad Nacional del Comahue, Roca (Río Negro), núm. 17, pp. 123-150.

Rafart, Gabriel (2018). “Neuquén y su transición, 1980-1983”, en Moroni, Marisa (Comp) Actores políticos y reorganización partidaria en la Patagonia, 19801983, La Pampa: Edit.Universidad Nacional de La Pampa.

Rafart, Gabriel y Mases, Enrique (2003). El Peronismo. Desde los territorios a la nación. Su historia en Neuquén y Río Negro, 1943-1958, Neuquén: Educo.

Servetto, Alicia (2010). 73/76: El gobierno peronista contra las 'provincias montoneras', Buenos Aires: Siglo XXI.

Vaccarisi, María Elizabeth y Campos, María Emilia (2010). “La oposición político partidaria ante un partido hegemónico. El curso y decurso del Partido Justicialista en un espacio subnacional, Neuquén, 1983-2003", en Favaro, Orietta y Iuorno, Graciela (eds.) El 'arcón'de la Historia Reciente en la Norpatagonia argentina, Buenos Aires: Biblos, pp. 55-89.

Vommaro, Gabriel (2006). “Cuando el pasado es superado por el presente: las elecciones presidenciales de 1983 y la construcción de un nuevo tiempo político en la Argentina", en Pucciarelli, Alfredo (coord.) Los años de Alfonsín. ¿El poder de la democracia o la democracia del poder?, Buenos Aires: Siglo XXI, pp. 245-288. 